\title{
Estimativas de vazões de lixiviados de um aterro sanitário na região metropolitana de Belém
}

\section{Estimates of flows leachates from a landfill in the metropolitan region of Belém}

Data de entrada: 20/11/2019

- Data de aprovação: 01/10/2020

Gabriela Rousi Abdon da Silva ${ }^{1 *}$ | Risete Maria Queiroz Leão Braga' 1

Lindemberg Lima Fernandes ${ }^{1}$ | Rafaela Nazareth Pinheiro de Oliveira Silveira ${ }^{2}$

DOI: https://doi.org/10.36659/dae.2022.021

ORCID ID

Silva GRA (D) https://orcid.org/0000-0001-8960-7076

Braga RMQ (D) https://orcid.org/0000-0003-4267-7426
Fernandes LL (ID) https://orcid.org/0000-0003-1806-4670

Silveira RNPO (D) https://orcid.org/0000-0002-0327-9663

\section{Resumo}

Os resíduos sólidos se apresentam como uma grande problemática ambiental na atualidade, haja vista a grande quantidade gerada e a consequente destinação incorreta. A Lei n 12.305/2010, que institui a Política Nacional de Resíduos Sólidos (PNRS), é bastante atual e contém instrumentos importantes para permitir o avanço necessário ao país no enfrentamento dos principais problemas ambientais, sociais e econômicos decorrentes do manejo inadequado dos resíduos sólidos. Um dos princípios da PNRS é reconhecer o resíduo como sendo reutilizável e reciclável e a disposição em aterros sanitários para os rejeitos. Para tanto, é necessário que os aterros tenham sistemas capazes de proteger e minimizar os impactos ambientais causados por essa disposição. Entre esses sistemas, destaca-se o de drenagem de lixiviado resultante da decomposição dos resíduos somado à precipitação pluviométrica. Nesse caso, a quantificação da vazão do percolado é um dos fatores principais na determinação do tratamento a ser dado para esse percolado. Portanto, esse estudo teve como objetivo avaliar a quantificação de lixiviado proveniente de um aterro na Região Metropolitana de Belém (RMB), a partir dos métodos empíricos de Balanço Hídrico e Suíço, comparando-os com a vazão real do percolado proveniente do aterro. Os dados da precipitação média anual utilizada foram de uma série de 2006 a 2017. Os resultados apontaram que, das vazões estimadas, a que mais se aproximou da vazão real e que abrangeu as situações de mínima, média e máxima vazão foi a determinada pelo método Suíço, quando aplicado um coeficiente de compactação de resíduos (K) igual a 0,25.

Palavras-chave: Aterros Sanitários. Método Suíço. Método Balanço Hídrico.

\section{Abstract}

Waste is a major environmental problem today, and there is a large amount generated and consequent incorrect destination. Law No. 12,305 / 2010, which establishes the National Solid Waste Policy (PNRS) is very current and contains important instruments to allow the necessary advance for the country in which there is no confrontation of environmental, social and economic problems. One of the principles of PNRS is the recognition or waste as reusable and recyclable and disposal in landfills for tailings. Therefore, landfills must have systems capable of protecting and

\footnotetext{
${ }^{1}$ Universidade Federal do Pará - Belém - Pará - Brasil.

${ }^{2}$ Universidade Federal do Sul e Sudeste do Pará - Marabá - Pará - Brasil.

* Autora correspondente: gabrielarousiabdonagmail.com.
} 
reducing the environmental impacts caused by this type of disposal. Among these systems, the leaching drainag system of system resulting from the decomposition of waste added to rainfall. In this case, the quantification of the outflow is one of the main determining factors for the treatment of the data. Therefore, this study aimed to evaluate the quantification of leachate in the Belém Metropolitan Region (RMB) using empirical Swiss and Water Balance methods, comparing them with actual outflow of landfill. Data from the annual average use of a short-term historical series from 2006 to 2017. The results shows of which outflows estimate most closely resemble actual outflows and which include the mean, maximum and maximum outflows situations were determined by the Swiss method, when applied a residual compaction coefficient $(K)$ is equal to 0.25 .

Keywords: Sanitary Landfills. Swiss Method. Water Balance Method.

\section{INTRODUÇãO}

O crescimento populacional e o desenvolvimento urbano são duas variáveis importantes quando se trata da problemática dos resíduos sólidos. Segundo HERNÁNDEZ-BERRIEL et al. (2017), a gestão integrada dos resíduos sólidos na América Latina continua sendo um tema não muito trabalhado, e ainda há tópicos que precisam ser discutidos, principalmente em países em desenvolvimento, onde é comum a disposição final dos resíduos sólidos urbanos (RSU) em lixões, aterros controlados e aterros sanitários sem tratamento prévio (IDOWU et al., 2019). Um desses tópicos é a participação do setor privado na gestão dos resíduos e a inclusão dos catadores nesse processo, influenciando diretamente na disposição final de rejeitos (SILVA e BOLSON, 2019; LEWIS e RAUTURIER, 2019).

No cenário atual nacional, a Associação Brasileira de Empresas de Limpeza Pública e Resíduos Especiais (Abrelpe), em seu panorama de Resíduos Sólidos no Brasil, do ano de 2018, estimou uma geração anual de 79 milhões de toneladas de resíduos no país, apresentando um aumento de aproximadamente $1 \%$ em relação ao ano anterior (ABRELPE 2018). Em vista dessa grande produção, é colocada em pauta a destinação ambientalmente adequada, o tratamento dos resíduos e a disposição final adequada de rejeitos, conforme disposto na Política Nacional dos Resíduos Sólidos (PNRS)-Lei nº 12.305/2010, a qual apresenta como solução para os rejeitos domiciliares a disposição em aterros sanitários (BRASIL, 2010).

Entretanto, o manejo e a disposição de resíduos, muitas vezes, não são condizentes com as normas e legislações, como é o caso dos países pertencentes ao BRIC (Brasil, Rússia, Índia e China), onde uma grande parte dos aterros não apresenta um ou mais sistemas adequados de instalação (GONÇALVES et al., 2018).

No Brasil, os aterros sanitários devem ser construídos tomando como normatização a Associação Brasileira de Normas Técnicas (ABNT):NBR 8419/1992, que aponta como devem ser previstos e executados os sistemas de drenagem superficial, drenagem e remoção de percolado, tratamento do lixiviado, impermeabilização inferior e/ou superior e drenagem de gás.

Segundo a Abrelpe, em 2018 foram coletados $92 \%$ dos resíduos gerados no país, sendo que $59,5 \%$ desses resíduos foram dispostos em aterros sanitários, o que representa 43,3 milhões de toneladas (ABRELPE, 2018). O Sistema Nacional de Informações sobre o Saneamento (SNIS), também para o ano de 2018, apontou que cerca de 75,6\% dos resíduos foram dispostos em 607 aterros sanitários, 24,4 \% dispostos em 1.037 lixões ou em 540 aterros controlados (SNIS, 2018). Ou seja, mais da metade de todos os resíduos coletados nos municípios brasileiros não são re- 
ciclados e acabam sendo dispostos em aterros, afetando o volume e a vida útil do sistema.

Dentre as regiões brasileiras, a região Norte é uma das que menos apresenta destinação correta para seus resíduos e apresenta poucos aterros sanitários. Em 2018, o SNIS apontou a existência de 16 aterros sanitários, 39 aterros controlados e 154 lixões, ou seja, é a região com menor número de aterros sanitários (2,64 \% do total nacional), em relação às 5 regiões do país (SNIS, 2018).

Um dos pontos mais importantes quanto à questão dos impactos ambientais relacionados aos aterros sanitários é o lixiviado resultante da biodegradação dos resíduos sólidos (NAVES, 2019; VACCARI; TUDOR; VINTI, 2019). A inexistência de um tratamento adequado para esse lixiviado pode gerar graves danos ambientais, como a poluição das águas subterrâneas e proliferação de vetores, o que acarreta um alto risco de contágio de doenças (SILVA e LIPORONE, 2011; QUINTERO e GONZÁLEZ, 2017; COSTA, et al., 2018).

Depois de implementado, o aterro deve possuir um sistema de tratamento do lixiviado, para que posteriormente seja despejado em corpo receptor. Brennan et al. (2017) relatam que o tratamento a ser realizado no lixiviado varia de acordo com a idade do líquido percolado; os mais jovens podem ser encaminhados ao tratamento junto aos residuários municipais, já os mais antigos precisam ser misturados aos mais jovens ou devem sofrer pré-tratamento. Vaccari, Tudor e Vinti (2019) pesquisaram as características do lixiviado de aterros sanitários na Ásia, África e América Latina, inclusive no Brasil, e apontaram que a concentração de poluentes advindos do lixiviado está relacionada às condições regionais (clima), aos padrões de consumo e hábitos quanto à gestão de resíduos no âmbito individual de casas e pessoas.
Os métodos convencionais de tratamento dos lixiviados costumam ser: transferência (tratamento do lixiviado junto ao esgoto doméstico), biodegradação (aeróbia e anaeróbia) e tratamentos físico/químicos (adsorção, coagulação, entre outros), sendo o tratamento biológico o mais utilizado, devido a sua confiabilidade e custo-benefício como relatam Renou et al. (2008). Cheibub, Campos e Fonseca (2014) explanam que para aterros jovens os tratamentos biológicos do lixiviado são eficientes, pois o líquido percolado de aterros novos apresenta grande concentração de demanda bioquímica de oxigênio (DBO). Já para lixiviados estabilizados, de aterros mais antigos, os tratamentos biológicos não são eficazes (LIMA et al., 2017).

Para um correto manejo e posterior tratamento do líquido percolado gerado, é vital que ocorra a quantificação do volume produzido e a análise química, avaliando a vazão esperada de produção do lixiviado e a sua composição, dando assim um embasamento para o tipo de tratamento mais adequado a ser utilizado e o correto dimensionamento da camada drenante (NAVES, 2019). Nesse contexto, existem três diferentes métodos passíveis de utilização para a estimativa de vazão de líquido residual a ser gerado em um aterro sanitário, denominados Método do Balanço Hídrico local, Método Suíço e Método Racional.

Diante do exposto, o presente trabalho teve como objetivo quantificar a vazão do lixiviado proveniente de um aterro de resíduos sólidos, localizado na RMB. No estudo foram comparadas a vazão real do lixiviado com as vazões obtidas pelos métodos empíricos do Balanço Hídrico e o método Suíço, com a finalidade de proporcionar embasamento teórico para futuros projetos de implementação de aterros no estado do Pará, tomando como fator principal a precipitação na área do aterro. 


\section{METODOLOGIA}

\section{1 Área de estudo}

O aterro está localizado no município de Marituba, RMB (Fig. 1). Segundo o Relatório de Impacto Am- biental (RIMA), o empreendimento possui uma área total de 110 ha e vida útil estimada em 15 anos e 5 meses, recebendo em média 1.200 toneladas/dia de resíduos classe II (Ampla Meio Ambiente, 2011).
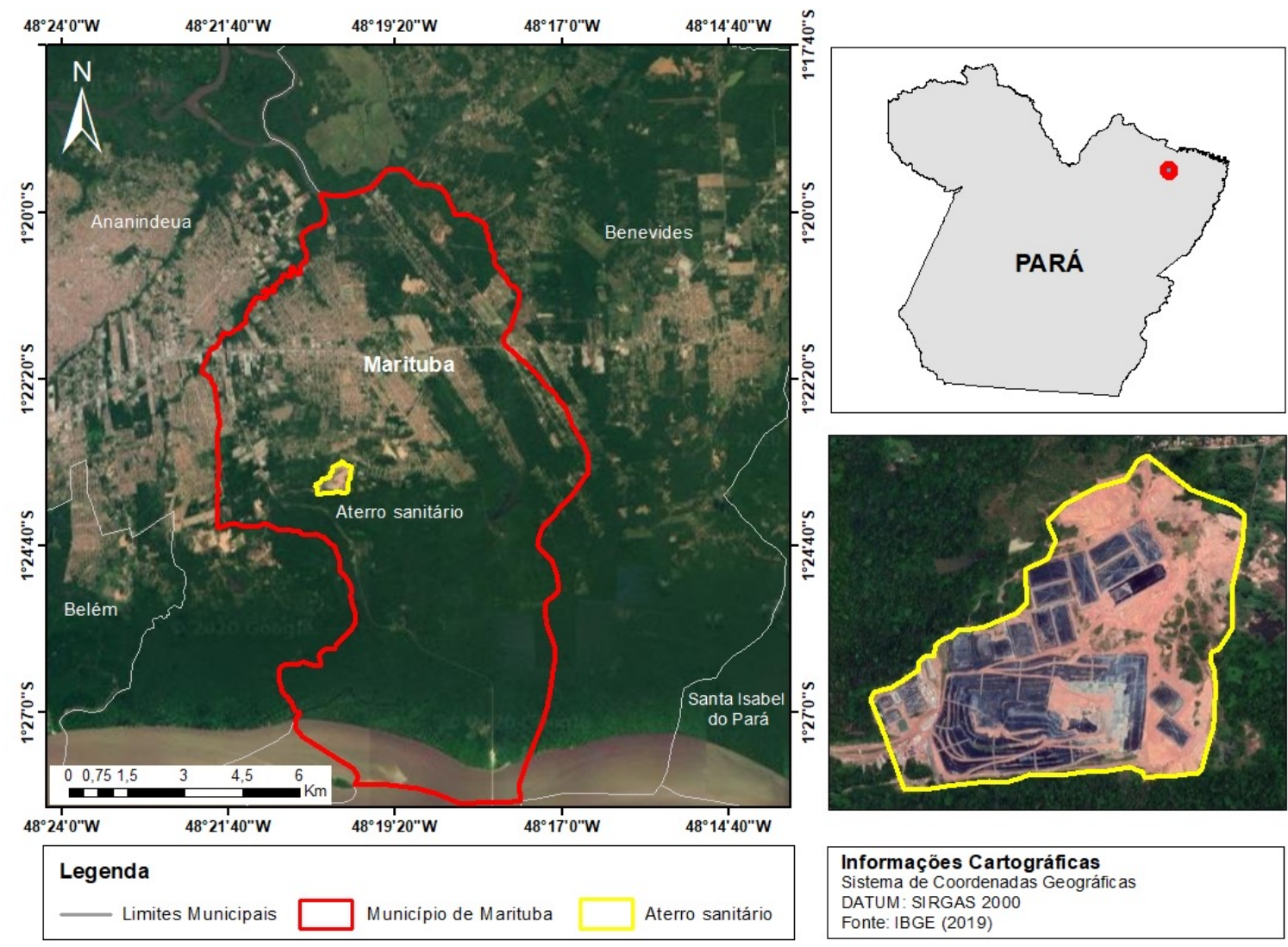

Figura 1 -Localização do aterro de Marituba.

Oliveira e Braga (2017) listaram que os municípios de Ananindeua, Belém e Marituba destinam os seus RSU para esse aterro desde 2016. De acordo com o RIMA, esse aterro é composto pelos sistemas de impermeabilização de fundo, drenagem e tratamento do lixiviado, drenagem e queima de gases e sistema de drenagem de águas pluviais.

\subsection{Procedimentos metodológicos}

O estudo seguiu basicamente três etapas principais: levantamento da série histórica dos dados pluviométricos (sendo considerada a precipitação acumulada anual no período de 2006 a
2017); utilização dos métodos de Balanço Hídrico e o Suíço para quantificação de vazão produzida, correlacionando os dados existentes entre a precipitação pluviométrica na região do aterro e a produção de lixiviados; e comparação dos resultados obtidos com os dados reais de vazão, a fim de avaliar o método mais representativo na determinação da produção de lixiviado.

\subsubsection{Aplicação dos Métodos do Balanço Hídrico e Suiço}

Para a determinação a vazão do lixiviado pelo método do Balanço Hídrico foi utilizada a Eq. 1. 


$$
Q=\frac{P E R * A}{T}
$$

Onde:

Q - Vazão (L/s)

PER - Percolado $(\mathrm{mm})$

A - Área do aterro $\left(\mathrm{m}^{2}\right)$

$\mathrm{T}$ - Segundos de um ano

Onde o PER pode ser obtido pela Eq. 2

$P E R=P-E S-\triangle A S-E R$

Onde:

PER - Percolado (mm/ano)

$P$ - Precipitação $(\mathrm{mm})$

ES - Escoamento superficial (Precipitação x Coeficiente de runoff) ( $\mathrm{mm}$ )

$\Delta$ AS - Variação do armazenamento de água no solo $(\mathrm{mm})$

ER - Evapotranspiração real

Os valores de evapotranspiração real, evapotranspiração potencial e precipitação foram obtidos por meio de dados do Instituto Nacional de Meteorologia (IMET). Os valores mensais foram acumulados para possibilitar a avalição da quantificação de lixiviado anual.

A precipitação pluviométrica acumulada anual no período de 2006 a 2017 foi considerada avaliando-se a vazão de lixiviado gerado por cada ano em questão. $O$ coeficiente de runoff para a área do aterro foi adotado $(0,20)$, característico para solos argilo-arenosos, seguindo o relatado por Costa (2001). O armazenamento anual de água no solo foi obtido por meio da média dos valores mensais fixos, considerando os meses de intensa e baixa precipitação, com um valor médio de $0,25 \mathrm{~mm}$.

Para o método Suíço a vazão foi determinada de acordo com a Eq. 3.
$Q=\frac{P * A * K}{t}$

Onde:

Q - Vazão média do percolado, lixiviado (L/s)

$P$ - Precipitação média anual $(\mathrm{mm})$

A - Área total do aterro $\left(\mathrm{m}^{2}\right)$

$T$ - Tempo (segundos)

$\mathrm{K}$ - Coeficiente que depende do grau de compactação dos resíduos, variando entre 0,15 e 0,5.

Os dados referentes da área do aterro, $328.900 \mathrm{~m}^{2}$, massa específica dos resíduos compactados nas células, de $1,10 \mathrm{t} / \mathrm{m}^{3}$, foram obtidos a partir da troca de informações, via correio eletrônico, com a gerência operante do aterro. O fator tempo foi empregado em segundos, referente a um ano.

Embora a massa específica dos resíduos esteja com valor superior a $0,7 \mathrm{t} / \mathrm{m}^{3}$, que é considerada um valor para aterro com resíduos bem compactado, de acordo com Rocca (1993), no estudo foi verificada a aplicação de três valores de k, considerando a compactação: baixa $(0,50)$; média $(0,25)$; e forte $(0,15)$; o que possibilitou uma avaliação do grau de influência desse coeficiente na estimativa de vazão de lixiviado no aterro.

Para o cálculo da precipitação média anual, maior precipitação, frequência e tempo de retorno de precipitações extremas, foram coletados os dados disponíveis de 1988 a 2017 na plataforma digital do INMET - estação pluviométrica de Belém n² 82.191, uma vez que o município de Marituba, onde está inserido o aterro, não possui estação cadastrada. A validação dos dados foi possível haja vista que a estação está situada a uma distância de $12 \mathrm{~km}$ da CPTR, estando assim em conformidade com o estabelecido e recomendado pela Organização Meteorológica Mundial (World Meteorological Organization - WMO) a qual apesenta, para estações pluviométricas, densidade máxima de cobertura de 10 a $20 \mathrm{~km}^{2}$ 
em zonas urbanas (WMO, 2008), que é o intervalo dentro da faixa de cobertura recomendada pelo Guia de Prática Hidrológicas da Organização Mundial de Meteorologia. A evapotranspiração real foi obtida por meio da soma dos dados mensais, gerando valores acumulados anuais, possibilitando assim o cálculo do volume gerado de percolado anualmente.

O método aplicado para determinar do período de retorno foi o de Kimball (VILLELA e MATTOS, 1975), e a frequência de ocorrência foi obtida por meio do método denominado Califórnia (VILLELA e MATTOS, 1975; PINTO et al.,1976; CRUCIA$\mathrm{NI}, 1986)$, sendo adequado para aplicação onde o período de retorno não seja maior que os anos de observação. Neste caso, as aplicações de ambos os métodos isenta a utilização de distribuição probabilística. Os dados pluviométricos diários coletados foram os dos últimos 12 anos para a estação, período compreendido de 1 janeiro de 2006 até o dia 31 de dezembro de 2017, para efeito comparativo das estimativas de vazões entre os métodos Suíço e Balanço Hídrico, uma vez que não existem dados de evapotranspiração, passíveis de aplicação do método do Balanço Hídrico anteriores a 2006, justificando assim a utilização da série.

Não houve dados históricos de medição de vazão em campo. Os valores considerados reais de vazão correspondem a dois períodos no ano, fornecidos pela administração do aterro; são eles: valores de 8,1 L/s (período chuvoso-vazão real máxima) e de 2,08 L/s (período seco-vazão real mínima). Também foi considerado um valor médio entre as duas vazões de 5,09 L/s (vazão real média).

\section{RESULTADOS}

\subsection{Análise pluviométrica}

Os valores das precipitações acumuladas anuais estão apresentados na Fig. 2. A média das precipitações acumuladas anuais para o período de 1988 a 2017 resultou no valor de $3.321,9 \mathrm{~mm}$. A maior precipitação acumulada foi observada no ano de 2013 com 3.775,60 mm.

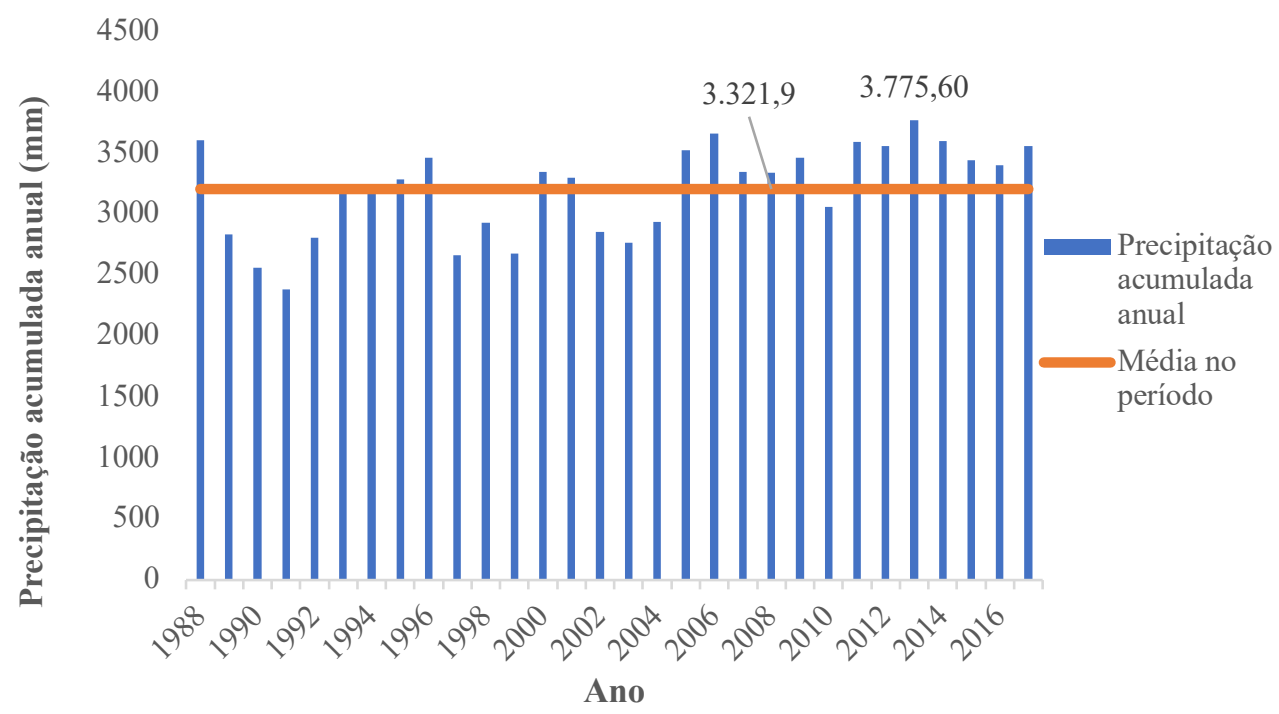

Figura 2 - Média das precipitações acumuladas anuais 
A partir desses dados foi possível organizar as precipitações e seus anos de ocorrência em ordem decrescente de grandeza (Tabela 1), considerando a precipitação como referência. É possível constatar que a maior precipitação apresentada na série histórica tem um tempo de retorno de 31 anos e não se repetirá durante o tempo de vida útil do aterro (que é de 2012 a 2027), conforme o RIMA (Ampla Meio Ambiente, 2011). As maiores precipitações, de acordo com o tempo de retorno, ocorrerão em 2022 (3.607,00 $\mathrm{mm})$ e 2027 (3.663,80 mm e $3.601,20 \mathrm{~mm})$.

Tabela 1- Ordem decrescente de precipitações anuais e os respectivos tempos de retorno.

\begin{tabular}{|c|c|c|c|}
\hline Ano & Precipitação (mm) & Frequência & Tempo de retorno (anos) \\
\hline 2013 & $3.775,60$ & 0,03 & 31 \\
\hline 2006 & $3.663,80$ & 0,06 & 16 \\
\hline 1988 & $3.607,00$ & 0,10 & 10 \\
\hline 2014 & $3.601,20$ & 0,13 & 8 \\
\hline 2011 & $3.593,10$ & 0,16 & 6 \\
\hline 2012 & $3.563,00$ & 0,19 & 5 \\
\hline 2017 & $3.560,90$ & 0,23 & 4 \\
\hline 2005 & $3.528,50$ & 0,26 & 4 \\
\hline 1996 & $3.464,60$ & 0,29 & 3 \\
\hline 2009 & $3.463,20$ & 0,32 & 3 \\
\hline 2015 & $3.445,20$ & 0,35 & 3 \\
\hline 2016 & $3.406,00$ & 0,39 & 3 \\
\hline 2000 & $3.352,10$ & 0,42 & 2 \\
\hline 2007 & $3.348,50$ & 0,45 & 2 \\
\hline 2008 & $3.339,60$ & 0,48 & 2 \\
\hline 2001 & $3.304,20$ & 0,52 & 2 \\
\hline 1995 & $3.290,30$ & 0,55 & 2 \\
\hline 1993 & $3.231,60$ & 0,58 & 2 \\
\hline 1994 & $3.226,70$ & 0,61 & 2 \\
\hline 2010 & $3.065,00$ & 0,65 & 2 \\
\hline 2004 & $2.940,20$ & 0,68 & 1 \\
\hline 1998 & $2.932,50$ & 0,71 & 1 \\
\hline 2002 & $2.856,00$ & 0,74 & 1 \\
\hline 1989 & $2.837,60$ & 0,77 & 1 \\
\hline 1992 & $2.810,50$ & 0,81 & 1 \\
\hline 2003 & $2.769,40$ & 0,84 & 1 \\
\hline 1999 & $2.677,30$ & 0,87 & 1 \\
\hline 1997 & $2.664,90$ & 0,90 & 1 \\
\hline 1990 & $2.561,30$ & 0,94 & 1 \\
\hline 1991 & $2.385,90$ & 0,97 & 1 \\
\hline
\end{tabular}

As precipitações entre os anos de 2006 e 2017, série utilizada para estimativa de vazões para os métodos Balanço Hídrico e Suíço, englobaram valores de precipitação variando de $3.065 \mathrm{~mm}$ a $3.775,6 \mathrm{~mm}$, ou seja, dentro do intervalo de ocorrência das maiores precipitações e o final de vida útil do aterro e que, portanto, valida a série utilizada no estudo.

\subsection{Aplicação do Método do Balanço Hídrico}

As estimadas de vazões do percolado em L/s obtidas pelo método do Balanço Hídrico estão apresentadas na Tabela 2, onde se percebe que as maiores vazões ocorreriam em 2006 e 2012, quando o aterro ainda não se encontrava em funcionamento. 
Tabela 2 - Estimativa de vazão pelo método do Balanço Hídrico.

\begin{tabular}{|c|c|c|c|c|c|c|c|c|c|c|c|c|}
\hline \multirow{2}{*}{ Parâmetros } & $\mathbf{2 0 0 1}$ Período - Anos & $\mathbf{2 0 1 3}$ & $\mathbf{2 0 1 3}$ & $\mathbf{2 0 1 6}$ & $\mathbf{2 0 1 7}$ \\
\hline PER (mm/ano) & $\mathbf{2 0 0 6}$ & $\mathbf{2 0 0 7}$ & $\mathbf{2 0 0 8}$ & $\mathbf{2 0 0 9}$ & $\mathbf{2 0 1 0}$ & $\mathbf{2 0 1 1}$ & $\mathbf{2 0 1 2}$ & $\mathbf{2 0 1 3}$ & $\mathbf{2 0 1 4}$ & $\mathbf{2 0 1 5}$ & $\mathbf{2 0 1 6}$ \\
\hline $\begin{array}{c}\text { Vazão estimada de } \\
\text { percolado (1/s) }\end{array}$ & $19,228,7$ & $1.277,8$ & $1.165,5$ & 771,1 & $1.261,1$ & $1.451,7$ & $1.336,7$ & $1.225,6$ & $1.162,9$ & 968,3 & $1.367,9$ \\
\hline
\end{tabular}

Nota-se que, por não ser um método que depende tão somente de área e da precipitação, sua maior estimativa não coincide com a do ano de maior precipitação acumulada.

\subsection{Aplicação do Método Suiço}

A partir da aplicação do Método Suíço e da variação do coeficiente $\mathrm{K}$, foi possível constatar a grande influência do mesmo na determinação da vazão de lixiviado. Para o ano de 2013, ano com maior valor de precipitação, os valores variaram de $5,9 \mathrm{~L} / \mathrm{s}$ até $19,7 \mathrm{~L} / \mathrm{s}$, ou seja, ao aplicar um $\mathrm{K}=$ 0,50 o valor de vazão é o triplo do encontrado ao aplicar um K = 0,15 (situação de melhor eficiência de compactação), resultando em uma diferença de 13,79 L/s. Na Fig. 3 é possível constatar as vazões estimadas em função da variação de valores de $\mathrm{K}$.

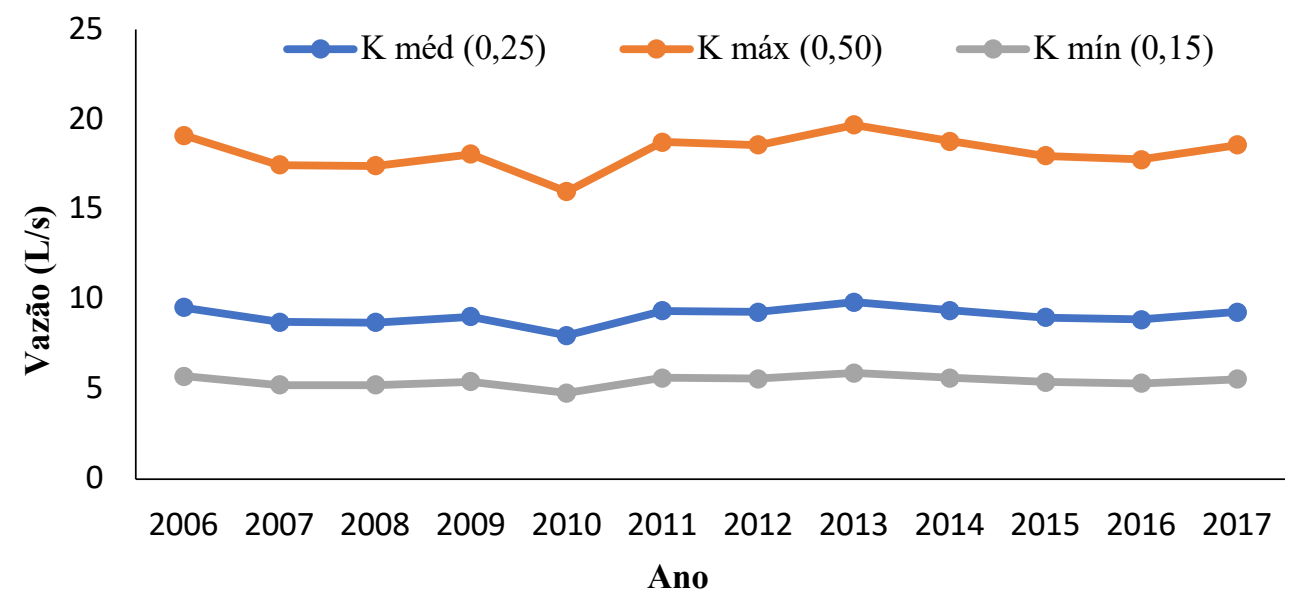

Figura 3 - Vazões estimadas pelo Método Suíço considerando diferentes K

\subsection{Comparativo entre as vazões estimadas e real}

É possível notar, a partir da comparação entre os resultados obtidos, que existe uma diferença expressiva entre as vazões estimadas pelos diferentes métodos, principalmente entre os valores para os aterros fortemente compactados $(K=0,15)$. Para o ano de maior precipitação (2013), a quantificação do percolado por meio do Método Suíço, utilizando $\mathrm{K}=0,15$ foi de $5,9 \mathrm{~L} / \mathrm{s}$, enquanto pelo método do Balanço Hídrico a vazão estimada chegou a 13,94 L/s, ou seja, um valor de vazão percolada de aproximadamente 2 vezes maior que pelo Suíço. Esse resultado pode ser explicado pelo fato de que no método do Balanço Hídrico o coeficiente de compactação não é considerado, sendo ele o principal interferente no transporte do lixiviado pela massa de resíduo compactado. 
Observa-se também que as vazões estimadas pelo método do Balanço Hídrico se apresentam em valores intermediários em comparação aos valores obtidos pelo Método Suíço quando se utiliza os valores de $\mathrm{K}=0,25$ e $\mathrm{K}=0,50$. Entretanto, os valores obtidos com $K=0,50$ não representam a realidade do aterro estudado, haja vista que pela massa específica dos resíduos obtida, após compactação dos resíduos (faixa de aterros fortemente compactados), o K se apresentou na faixa de 0,15 a 0,25. A maior proximidade entre os valores obtidos de vazões, a partir dos dois métodos, foi encontrada no ano de 2010, onde para um $\mathrm{K}=0,25$ pelo Método Suíço e para o Método do Balanço Hídrico as vazões obtidas foram de $8,0 \mathrm{~L} / \mathrm{s}$ e $8,04 \mathrm{~L} / \mathrm{s}$, respectivamente. Os resultados da comparação entre as vazões reais e as vazões estimadas pelos Métodos Suíço e de Balanço Hídrico estão apresentados na Fig. 4.

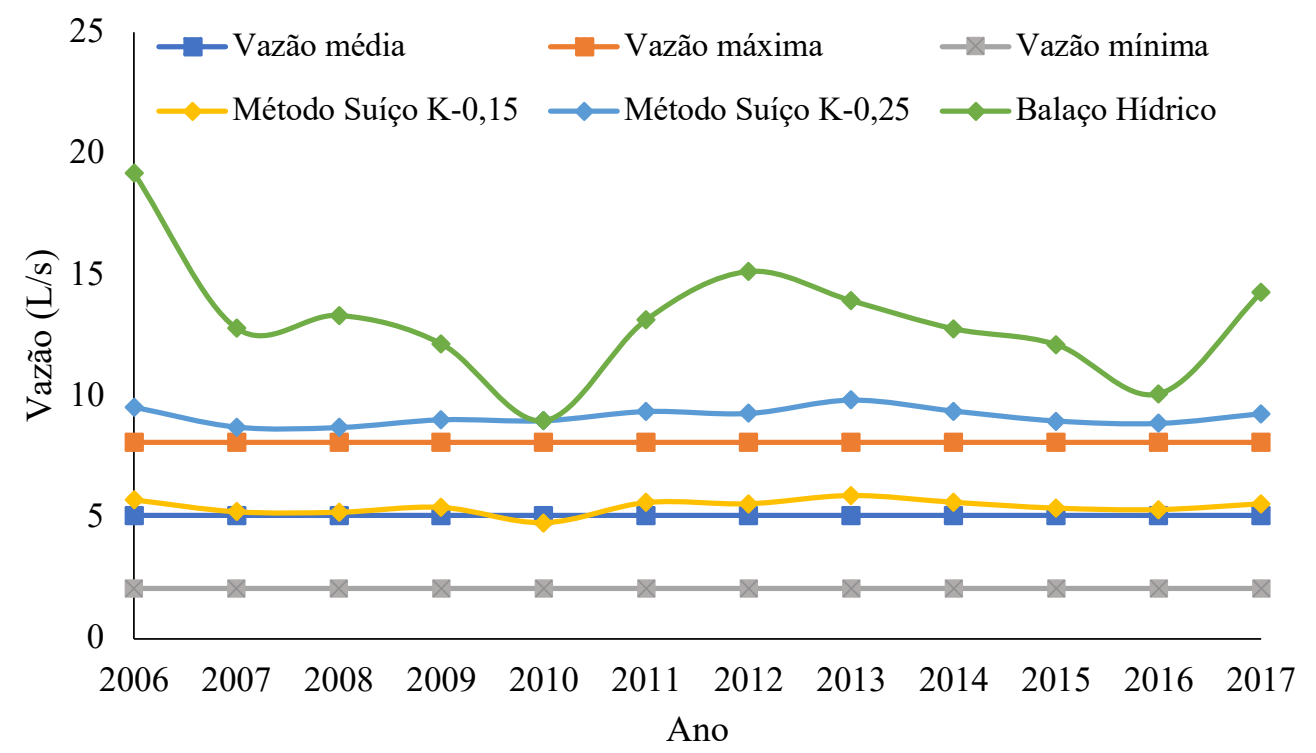

Figura 4 - Comparativo entre as vazões estimadas (Métodos Suíço e Balanço Hídrico) e as vazões reais (mínima, média e máxima).

É possível observar que os valores reais de vazão do percolado estão mais próximos dos valores estimados pelo Método Suíço para um $\mathrm{K}=0,15$. Já para o método de Balanço Hídrico as vazões reais são inferiores às estimadas, indicando uma superestimação de vazão de percolado para esse método.

\section{DISCUSSÃO}

Silva et al. (2016) relatam que ao estudar estimativas de vazões pelos métodos Suíço, Balanço Hídrico e Racional para o lixiviado provenientes de um aterro da região de Lajes no Rio de Janeiro, o método Suiço foi o único a apresentar correlação linear com a precipitação para uma série curta (maio de 2004 e abril de 2005) e também foi o que mais se ajustou com erro percentual médio de $21 \%$ abaixo da vazão real.

Considerando estimativa de vazões calculadas pelos métodos empírico Suíço e Balanço Hídrico, foi possível comparar, em percentual, a diferença entre os valores reais de vazões máximas, médias e mínimas, correlacionando com precipitações máximas, médias e mínimas (Tabela 3). 
Tabela 3 - Percentual de diferença entre as vazões estimadas pelos métodos Suíço e Balanço Hídrico com as vazões reais em L/s.

\begin{tabular}{|c|c|c|c|c|c|c|c|c|c|}
\hline \multirow{2}{*}{$\begin{array}{c}\text { Valores } \\
\text { estimados } \\
\text { de vazão }\end{array}$} & \multicolumn{3}{|c|}{ QMS } & \multirow{2}{*}{ QBH } & \multirow{2}{*}{ QR } & \multicolumn{3}{|c|}{ QR - QMS } & \multirow{2}{*}{ QR - QBBH } \\
\hline & K-0,15 & K-0,25 & K-0,50 & & & K-0,15 & K-0,25 & K-0,50 & \\
\hline Mínima & 4,8 & 8,0 & 16,0 & 8,04 & 2,08 & $57 \%$ & $74 \%$ & $87 \%$ & $74 \%$ \\
\hline Média & 5,45 & 9,09 & 18,2 & 13,09 & 5,09 & $7 \%$ & $44 \%$ & $72 \%$ & $61,12 \%$ \\
\hline Máxima & 5,9 & 9,8 & 19,7 & 13,09 & 8,1 & $-37 \%$ & $18 \%$ & $59 \%$ & $57,81 \%$ \\
\hline
\end{tabular}

Onde: $\mathrm{QMS}=$ vazão obtida pelo método Suíço; $\mathrm{QBH}=$ vazão obtida pelo método Balanço Hídrico; $Q \mathrm{R}=$ vazão real.

Ao comparar a vazão real média $(5,09 \mathrm{~L} / \mathrm{s})$ com a vazão obtida pelo Método Suíço para um valor de $K=0,15$, verifica-se um menor percentual de erro (7\%) em relação às demais vazões. Para a vazão real máxima, o método que estimou valores mais aproximados foi o método Suíço, com $K=0,25$, apresentando uma diferença de apenas $18 \%$.

Para o método de estimativa de vazão por Balanço Hídrico, o percentual mais próximo (58\%) foi o da vazão real máxima de $8,1 \mathrm{~L} / \mathrm{s}$. Destaca-se que, para uma vazão real mínima (período seco), todos os métodos apresentaram percentuais de vazão estimada bem distantes dos reais.

$\mathrm{Na}$ Tabela 4 estão apresentados os percentuais de erros encontrados entre as vazões estimadas pelos métodos de Balanço Hídrico e Suíço com as vazões reais em outros estudos de autores referenciadas por Gomes (2005) e o presente estudo, considerando o método Suíço com $\mathrm{K}=0,50$ e a vazão média real como referência.

Tabela 4 - Erros encontrados em métodos empíricos de estima de vazão para diversos autores.

\begin{tabular}{|c|c|c|}
\hline Autor/Método & Balanço Hídrico & Suíço \\
\hline Capelo Neto et al. (1999) & 80 vezes maior que a vazão real & 84 vezes maior que a vazão real \\
\hline Castro (2001) & $44 \%$ abaixo da vazão real & $58 \%$ acima da vazão real \\
\hline Jucá (2003) & $58 \%$ & $39 \%$ \\
\hline Lins (2003) & $25,91 \%$ abaixo da vazão real & $64,14 \%$ abaixo da vazão real \\
\hline Gomes (2005) & $34 \%$ acima da vazão real & $13 \%$ acima da vazão real \\
\hline Estudo & $61,12 \%$ acima da vazão real & $72,02 \%$ acima da vazão real \\
\hline
\end{tabular}

Fonte: Adaptado de Gomes (2005)

Quando comparadas as vazões reais com os valores obtidos por meio do Método Suíço por Gomes (2005), Jucá (2003), Castro (2001) e o presente trabalho, é possível observar que os resultados encontrados estão bem acima da faixa de porcentagem apresentada pelos autores em questão (13\%, 39\% e 58\%, respectivamente). Esse fato pode ser justificado pelo fato de a vazão real de lixiviado ser gerada em situação de forte compactação, ou seja, para $\mathrm{K}$ na faixa de 0,15 a 0,25, e não para $K=0,50$, que é o valor de coeficiente considerado por esses autores.
O resultado que mais se aproximou dos resultados obtidos por Gomes (2005) foi o encontrado a partir do Método Suíço para $K=0,25$, com porcentagem de diferença $18 \%$ com relação à vazão real máxima.

A aplicação do método do Balanço Hídrico resultou em vazões variando de $8,04 \mathrm{~L} / \mathrm{s}$ a 19,20 $\mathrm{L} / \mathrm{s}$, com um valor médio de 13,09 L/s. Aplicada a vazão máxima, apresentou porcentagens de diferença (-37\%), próximo aos resultados obtidos por Lins (2003) e Castro (2001), segundo o apresentado na tabela de Gomes (2005). 


\section{CONCLUSÃO}

A partir dos dados pluviométricos, é possível concluir que durante o tempo de vida útil do aterro, 15 anos, definido no RIMA do aterro estudado, a possibilidade de ocorrer precipitações acima de $3.663,80 \mathrm{~mm}$ é quase nula, haja vista que o tempo de retorno para um estudo de série de precipitação longa (1988-2017) ocorreu em 2013, ou seja, o maior valor de precipitação considerado para a estimativa de vazão de percolado no aterro para o período estudado de 2006 a 2017. Nesse período, a faixa pluviométrica variou entre $2.385,90 \mathrm{~mm}$ e $3.775,60 \mathrm{~mm}$, resultando em uma precipitação anual média de $3.321,9 \mathrm{~mm}$.

Ao comparar as quantificações empíricas de vazões usando dois métodos (Suíço e Balanço Hídrico), verifica-se que o método que mais se aproximou dos valores reais de vazão na área do aterro foi o Método Suíço, quando utilizado um valor de $K=0,15$. Entretanto, os resultados para essa faixa da compactação não abrangem a vazão real máxima, ou seja, caso o projeto se baseie somente nessa quantificação, as caneletas podem não suportar a vazão de pico, o que acarretaria problemas futuros no tratamento dos efluentes. Sendo assim, o método que abrange todas as faixas de vazão real é o Método Suíço para um coeficiente $\mathrm{K}=0,25$.

Assim, o estudo contempla que, para um futuro projeto de aterro e sua implantação na RMB, indica-se a utilização do Método Suíço para as estimativas de vazão do percolado do aterro. Ressalta-se que previamente seja estabelecido o coeficiente de compactação, que será empregado para compactação dos resíduos nas células, para que as caneletas de drenagem sejam dimensionadas de maneira correta sem um superdimensionamento ou subdimensionamento, diminuindo assim o risco de problemas de colmatação, extravasamentos e perdas econômicas, relacionadas à drenagem de lixiviados.
É importante que se realize um estudo com uma medição de vazões em campo por um período maior, estabelecendo as diferenças mensais de precipitação, a fim de que sejam analisados os métodos com mais precisão. Deve-se também aplicar em estudos futuros uma análise mais realista dos dois métodos; um dos fatores a serem melhorados é a área a ser considerada do aterro. Neste estudo foi considerada a área total do aterro, sem fazer distinção das células que estavam em operação e suas áreas específicas.

Por fim, o estudo apresenta como indicação de melhor método pera estudos de implementação de aterros no estado do Pará o Método Suíço com coeficiente $\mathrm{K}=0,25$. Entretanto, para a aplicação desse coeficiente recomenda-se que os novos aterros sanitários sejam construídos em áreas que apresentem características físicas e climáticas similares às da RMB; além de projetos com grau de compactação semelhante ao empregado no aterro CPTR Marituba.

\section{CONTRIBUIÇÃO DOS AUTORES}

Todos os autores contribuíram de forma igualitária.

\section{REFERÊNCIAS}

ABRELPE-Associação Brasileira de Empresas de Limpeza Pública e Resíduos Especiais. Panorama de Resíduos Sólidos no Brasil, 2018-2019. Disponível em < https://abrelpe.org.br/ download-panorama-2018-2019/>. Acesso em: 25 de agosto de 2020.

ASSOCIAÇÃO BRASILEIRA DE NORMAS TÉCNICAS, NBR. 8419: Apresentação de projetos de aterros sanitários de resíduos sólidos urbanos. Rio de Janeiro, 1992.

BRASIL. Política Nacional de Resíduos Sólidos. Lei n 12.305 , de 2 de agosto de 2010. Disponível em: http://www.planalto. gov.br/ccivil_03/_ato2007-2010/2010/lei/l12305.htm. Acesso em: 10 de julho de 2019.

BRENNAN, Raymond B. et al. Treatment of landfill leachate in municipal wastewater treatment plants and impacts on effluent ammonium concentrations. Journal of environmental management, v. 188, p. 64-72, 2017. Disponível em: <https:// 
doi.org/10.1016/j.jenvman.2016.11.055>Acesso em: 10 de julho de 2019.

CHEIBUB, A. F.; CAMPOS, J. C.; DA FONSECA, F. V. Removal of COD from a stabilized landfill leachate by physicochemical and advanced oxidative process. Journal of Environmental Science and Health, Part A, v. 49, n. 14, p. 1718-1726, 2014. Disponível em: < https://doi.org/10.1080/10934529.2014.951259> Acesso em: 14 de agosto de 2019.

COSTA, M. D., MARIANO, M. O. H., ARAUJO, L. B., \& JUCÁ, J. F. T. Estudos laboratoriais para avaliação do desempenho de camadas de cobertura de aterros sanitários em relação à redução de emissões de gases e infiltrações. Engenharia Sanitária e Ambiental, 23(1), 77-90,2018.Disponível em: < https://doi. org/10.1590/S1413-41522018160393 >. Acesso em 24 de juIho 2020.

COSTA, T. C. D. Análise Crítica das Metodologias Gerais de Mapeamento Geotécnico Visando a Formulação de Diretrizes para a Cartografia Geotécnica no Trópico Úmido e Aplicação na Região Metropolitana de Belém, Escala 1:50.000. 2001. 256 f. Tese (Doutoradoem Geociências), Universidade Federal do Pará, Belém, 2001.

DA SILVA, C. B.; LIPORONE, F. Deposição irregular de resíduos sólidos domésticos em Uberlândia: algumas considerações. OBSERVATORIUM: Revista Eletrônica de Geografia, v. 2, n. 6 , 2011. Disponível em: <http://www.seer.ufu.br/index.php/Observatorium/article/ view/45058/24012> Acesso em: 12 de agosto de 2019.

GOMES, T. L. Avaliação quali-quantitativa do percolado gerado no aterro controlado de Santa Maria RS. Campo Grande, Brasil, 2005. Disponível em:< https://repositorio.ufsm.br/handle/ 1/7670> Acessado em: 11 de outubro de 2018.

GONÇALVES, A. T. T.; MORAES, F. T. F.; MARQQUES, G. L.; et al. Urban solid waste challenges in the BRICS countries: a systematic literature review. Ambiente e Água - An Interdisciplinary Journal of Applied Science, v. 13, n. 2, p. 1, 2018. Disponível em:< https://doi.org/10.4136/ambi-agua.2157 > . Acesso em: 3 abr. 2019.

HERNÁNDEZ-BERRIEL D. C.M. et al. Generación y composición de los residuos sólidos urbanos en América Latina y el Caribe. Revista internacional de contaminación ambiental, v. 32, p. 11-22, 2017. Disponível em:< https://doi.org/0.20937/ RICA.2016.32.05.02 > Acesso em: 15 de agosto de 2019 .

IDOWU, I. A., ATHERTON, W., HASHIM, K., KOT, P., ALKHADDAR, R., ALO, B. I., \& SHAW, A. An analyses of the status of landfill classification systems in developing countries: Sub Saharan Africa landfill experiences. Waste Management, v. 87, p. 761771, 2019. Disponível em: < https://doi.org/10.1016/j.wasman.2019.03.011> https://www-sciencedirect.ez3.periodicos.
capes.gov.br/science/article/pii/S0956053X19301321?via\%3Dihub. Acesso em: 23 de agosto de 2020.

LEWIS, T.; RAUTURIER, F.. Respigando ao redor do globo: Reformulando a economia urbana por meio de práticas e economias de reutilização de lixo sólido. Journal of Consumer Culture, v. 19, n. 4, pág. 493-512, 2019. Disponível em:< https://doi. org/10.1177/1469540519872072> . Acesso em: 24 de julho de 2020 .

LIMA, L. S. M. S.; ALMEIDA, R. D.; QUINTAES, B. R.; BILA, D. M.; CAMPOS, J. C. (2017). Análise de metodologias de quantificação de substâncias húmicas em lixiviados de aterros de resíduos sólidos. Revista Ambiente \& Água, v. 12, n. 1, p. 87-98, 2017. Disponível em:< https://doi.org/10.4136/ambi-agua.1972 > . Acesso em:23 de julho de 2020.

NAVES, L. C. Influência da compactação do solo sobre a produção e o potencial poluidor de lixiviados de resíduos sólidos urbanos. Engenharia Sanitária e Ambiental, v. 24, n. 5, p. 949 958, 2019. Disponível em:< https://doi.org/10.1590/S141341522019118989 >. Acesso em 24 de julho de 2020.

OLIVEIRA, R. F., BRAGA. R.M.Q. de L. Sistema de cobertura final de um aterro sanitário para a RMB de Belém-PA com emprego de resíduos da construção civil. Revista Gestão \& Sustentabilidade Ambiental 6.3 (2017): 573-596. Disponível em: < http:// dx.doi.org/10.19177/rgsa.v6e32017573-596 >. Acessado em: 12 de outubro de 2018.

QUINTERO R. A.; VALENCIA G. Y.; LARA V. L. A. Efecto de los lixiviados de residuos sólidos en un suelo tropical. DYNA, v. 84 , n. 203, p. 283-290, 2017. Disponível em: < https://doi. org/10.15446/dyna.v84n203.63875> . Acesso em: 3 abr. 2019.

RENOU, S. et al. Landfill leachate treatment: review and opportunity. Journal of hazardous materials, v. 150, n. 3, p. 468493, 2008. Disponível em: < https://doi.org/10.1016/j.jhazmat.2007.09.077 > Acesso em: 22 de agosto de 2019.

SAAD, M. Resíduos Sólidos. Disponível em: <https://www. mma.gov.br/mma-em-numeros/residuos-solidos>. Acesso em: 19 ago. 2019.

SILVA, L. C.; BOLSON, C. Public Policy for Solid Waste and the Organization of Waste Pickers: Potentials and Limitations to Promote Social Inclusion in Brazil. Recycling, v. 3, n. 3, p. 40, 2018. Disponível em:< https://doi.org/10.3390/recycling3030040>. Acesso em: 25 de agosto de 2020.

SNIS - Sistema Nacional de Informações em Saneamento Básico. Diagnóstico do Manejo de Resíduos Sólidos, 2018. Brasil, Brasília, DF, 2018. Disponível em <http://www.snis.gov.br/ diagnostico-anual-residuos-solidos/diagnostico-do-manejo-de-residuos-solidos-urbanos-2018>. Acesso em: 25 de agosto de 2020. 
VACCARI, M.; TUDOR, T.; VINTI, G.. Características do lixiviado de aterros sanitários e lixões na Ásia, África e América Latina: uma visão geral. Gerenciamento de resíduos, v. 95, p. 416431, 2019. Disponível em:< https://doi.org/10.1016/j.wasman.2019.06.032> Acesso em: 25 de agosto de 2020.
VILLELA, M. S.; MATTOS, A. Hidrologia aplicada. São Paulo: McGraw-Hill do Brasil, 1975. 245 p.

WMO. World Meteorological Organization, 2008. Guide to Hydrological Practices, WMO, n 168 , Sixth Edition, Geneva. Disponível em: <http://www.whycos.org/hwrp/guide/index.php> Acesso em: 10 de janeiro de 2019. 